\title{
Anti-CTLA-4 Monoclonal Antibody REGN4659
}

National Cancer Institute

\section{Source}

National Cancer Institute. Anti-CT LA-4 Monoclonal Antibody REGN4659. NCI Thesaurus.

Code C159764.

A fully human immunog lobulin G1 (IgG1) antibody directed against the human T-cellexpressed receptor cytotoxic T-lymphocyte-associated antigen 4 (CT LA4; CT LA-4), with potential immune checkpoint inhibitory and antineoplastic activities. Upon intravenous administration, anti-CT LA-4 monoclonal antibody REGN4659 targets and binds to CT LA4 expressed on T-cells and inhibits the CT LA-4-mediated downregulation of T-cell activation. This leads to a cytotoxic T-lymphocyte (CTL)-mediated immune response against cancer cells. CT LA-4, an inhibitory receptor and member of the immunoglobulin superfamily (IgSF), plays a key role in the downregulation of the immune system. 